\title{
Regional differences in severe postpartum hemorrhage: a nationwide comparative study of 1.6 million deliveries
}

\author{
Babette W Prick ${ }^{1,2}$, Joost F von Schmidt auf Altenstadt ${ }^{3}$, Chantal WPM Hukkelhoven ${ }^{4}$, Gouke J Bonsel ${ }^{1}$, \\ Eric AP Steegers ${ }^{1}$, Ben W Mol', Joke M Schutte ${ }^{6}$, Kitty WM Bloemenkamp ${ }^{3}$ and Johannes J Duvekot ${ }^{1 *}$
}

\begin{abstract}
Background: The incidence of severe postpartum hemorrhage (PPH) is increasing. Regional variation may be attributed to variation in provision of care, and as such contribute to this increasing incidence. We assessed reasons for regional variation in severe PPH in the Netherlands.

Methods: We used the Netherlands Perinatal Registry and the Dutch Maternal Mortality Committee to study severe PPH incidences (defined as blood loss $\geq 1000 \mathrm{~mL}$ ) across both regions and neighborhoods of cities among all deliveries between 2000 and 2008. We first calculated crude incidences. We then used logistic multilevel regression analyses, with hospital or midwife practice as second level to explore further reasons for the regional variation.

Results: We analyzed 1599867 deliveries in which the incidence of severe PPH was 4.5\%. Crude incidences of severe PPH varied with factor three between regions while between neighborhoods variation was even larger. We could not explain regional variation by maternal characteristics (age, parity, ethnicity, socioeconomic status), pregnancy characteristics (singleton, gestational age, birth weight, pre-eclampsia, perinatal death), medical interventions (induction of labor, mode of delivery, perineal laceration, placental removal) and health care setting.

Conclusions: In a nationwide study in The Netherlands, we observed wide practice variation in PPH. This variation could not be explained by maternal characteristics, pregnancy characteristics, medical interventions or health care setting. Regional variation is either unavoidable or subsequent to regional variation of a yet unregistered variable.
\end{abstract}

Keywords: Cohort study, Postpartum hemorrhage, Geographic distribution, Epidemiology, Maternal mortality

\section{Background}

Severe postpartum hemorrhage (PPH) is a major obstetric complication and an important cause of maternal morbidity and mortality worldwide [1-4]. It is reported to occur in $2-6 \%$ of pregnancies $[3,5]$ and its incidence has increased over the last decade [6-13]. The World Health Organization defines severe PPH as blood loss of $\geq 1000 \mathrm{~mL}$ [14], independent of the mode of delivery, i.e. vaginal delivery or Cesarean Section (CS).

Carolli reported variation in severe $\mathrm{PPH}$ incidence worldwide varying from 0.3 to $3.8 \%$ in Africa, 0.7 to $2.7 \%$

\footnotetext{
*Correspondence: j.j.duvekot@erasmusmc.nl

'Department of Obstetrics and Gynecology, Division of Obstetrics \& Prenatal Medicine, Erasmus MC, 's-Gravendijkwal 230, 3015, CE Rotterdam, The Netherlands

Full list of author information is available at the end of the article
}

in Asia and 1.7 to 5.5\% in Europe [5]. Since the incidence of severe PPH in several developed countries is increasing, its assessment at the national and regional levels is important. Intercountry variation, particularly between developed and developing countries, may result from differences in medical interventions or health care systems. At a national level, regional differences are also observed, for example in California, where 3-fold differences among regions have been reported [15]. Exploring reasons for these differences is crucial before improvements in clinical practice can be established. Differences in populations may be an explanation for the variation in severe $\mathrm{PPH}$ between countries and regions. For this reason, adjustments for the characteristics of mothers and pregnancies seem necessary for a better understanding of the variation. 
In this paper, we studied the incidence of severe PPH in the 12 provinces and four largest cities in the Netherlands, as well as in the neighborhoods of the two largest cities. We hypothesized that variation may be due to the combined effect of maternal and pregnancy characteristics, medical interventions and variation in PPH policy in hospital and community midwife practices. As PPH-related mortality accounts for almost $8 \%$ of all direct maternal deaths in the period 1993-2005 [16], we also studied the severe PPH-related mortality per region.

\section{Methods}

We studied all deliveries registered in the Netherlands Perinatal Registry (PRN) in the period 2000-2008. Deliveries with a gestational age below $24^{+0}$ weeks were excluded. We studied the period 2000-2008 as during collection and analyses the data regarding more recent years were not available. The PRN is a linked national registry in which information on $96 \%$ of all pregnancies and pregnancy outcomes are registered by care providers [17]. Predefined information is directly extracted from the mothers' record and sent to the PRN. The PRN registers both data from community midwife practices (LVR1, primary care) providing care to women with low-risk pregnancies and data from hospitals providing care to women with an increased perinatal risk by obstetricians (LVR2, secondary/ tertiary care). Data on active third stage management and professional performance are not available. Neonatal admissions and complications are registered by pediatricians (LNR) and are also incorporated in this registry [17]. Data presented in this study were anonymized: they cannot be related to individual women.

This study was approved by the privacy committee of the PRN. Ethical approval is not needed for this type of study in the Netherlands.

The Netherlands comprises 12 provinces. The eight tertiary care hospitals are located in six of the provinces (Noord-Holland, Zuid-Holland, Utrecht, Gelderland, Limburg and Groningen) while teaching hospitals are present in all provinces. In three of the four largest cities (Amsterdam, Rotterdam and Utrecht) a tertiary care hospital is located while The Hague, the fourth largest city, lacks such a facility. In the Netherlands women with low-risk pregnancies deliver under responsibility of independent community midwife practices or general practitioners. Of these low-risk women $76 \%$ deliver at the hospital and 24\% deliver at home (Table 1) [18]. Women with high-risk pregnancies are cared for by gynecologists and deliver in hospital.

The incidence of severe PPH was analyzed per province and in the four largest cities because previous studies reported that perinatal outcomes in these cities are inferior to those in the other regions (provinces) of the Netherlands [19-21]. For the two largest cities, Amsterdam and Rotterdam, the incidence of severe PPH was analyzed across neighborhoods. Women were classified as part of every province, city and neighborhood using the four-digit zip codes of the women's address as geographical classifier. Therefore, a woman from a rural area, delivering in a tertiary hospital, was analyzed as woman from that rural region. Maternal mortality numbers were independently obtained from the Maternal Mortality Committee of the Dutch Society of Obstetrics and Gynecology [16].

\section{Statistical analysis}

We studied crude incidence of severe PPH across Dutch provinces, in the four largest cities, and across neighborhoods in the two largest cities (Amsterdam and Rotterdam). PPH-related maternal mortality across regions was studied in a similar way. Crude severe PPH incidences were tabulated, as well as crude incidences after exclusion of multiple pregnancies. Data were stratified for mode of delivery as PPH incidence varies according to mode of delivery [22].

The distribution of the severe PPH incidences was projected on a map of the Netherlands. For this figure, quartiles of incidences were chosen as cutoffs. We performed logistic multilevel regression analyses to explore the origin of the observed geographical variation using hospitals and community midwife practices as the second level in these analyses. For this purpose, each hospital and community midwife practice was labeled using an anonymized code.

We performed six model specifications following the same pattern and all models were fit on the exact same data. First, we estimated a model including regions only to assess the outcome (incidence of severe PPH) across regions. Then, we repeated the analysis after addition of covariates, which were added block-wise. Every subsequent model thus consisted of the first model and one specific block of covariates. The second model included maternal characteristics (age, parity, ethnicity, socioeconomic status [SES]) as covariates, the third model pregnancy characteristics (singleton, gestational age, birth weight, pre-eclampsia, perinatal death), the fourth model medical interventions (induction of labor, mode of delivery, perineal laceration, placental removal) and the fifth model health care setting (place of delivery). Finally, the last model was estimated after inclusion of all blocks (maternal characteristics, pregnancy characteristics, medical interventions and health care setting).

We used the following definitions. Severe PPH was defined as peripartum blood loss $\geq 1000 \mathrm{~mL}$ in the 24 hours following delivery. We categorized maternal age in $\leq 35$ and $>35$ years and parity into nulliparous women (i.e., 
Table 1 Maternal characteristics, pregnancy characteristics, medical interventions, health care setting and severe $\mathrm{PPH}$ incidences

\begin{tabular}{|c|c|c|c|c|}
\hline II & Spontaneous & $\begin{array}{l}\text { Assisted vaginal } \\
\text { delivery }\end{array}$ & Elective CS & Emergency CS \\
\hline PPH in & PPH incidence & PPH incidence & PPH incidence & $\%$ \\
\hline
\end{tabular}

Maternal characteristics

Age, n (\%)

$\leq 35$ years

$85.6 \quad 4.4$

$86.0 \quad 4.3$

$88.4 \quad 6.2$

$78.9 \quad 3.9$

$83.6 \quad 3.0$

$>35$ years

$14.4 \quad 5.1$

$14.0 \quad 4.8$

$11.6 \quad 7.7$

$21.1 \quad 5.5$

$16.4 \quad 4.3$

Parity

0

$\begin{array}{ll}46.2 \quad 5.0 \\ 53.8 & 4.0\end{array}$

39.15 .1

$82.1 \quad 6.6$

$42.0 \quad 3.8$

$67.7 \quad 2.8$

$\geq 1$

$60.9 \quad 3.9$

$17.9 \quad 5.5$

$58.0 \quad 4.6$

$32.3 \quad 3.9$

Ethnicity

Western

$84.5 \quad 4.6$

$83.9 \quad 4.4$

$88.2 \quad 6.6$

$86.7 \quad 4.1$

$83.5 \quad 3.2$

Non-Western

$\begin{array}{ll}15.5 & 4.1\end{array}$

$16.1 \quad 4.0$

$11.8 \quad 4.8$

$13.3 \quad 5.3$

$16.5 \quad 3.3$

Social economic status

Highest (> p 80)

$17.2 \quad 4.9$

$17.0 \quad 4.7$

$18.2 \quad 7.2$

$18.0 \quad 4.7$

$17.0 \quad 3.3$

Moderate (p20-80)

$57.8 \quad 4.5$

$57.8 \quad 4.3$

$58.4 \quad 6.4$

$58.9 \quad 4.1$

$\begin{array}{ll}57.0 & 3.2\end{array}$

Lowest $(<$ p20)

$25.0 \quad 4.2$

$25.3 \quad 4.2$

$23.1 \quad 4.2$

$26.0 \quad 3.0$

Pregnancy characteristics

Singleton pregnancy

$98.0 \quad 4.3$

$98.6 \quad 4.2$

$98.2 \quad 6.2$

$94.1 \quad 3.5$

$96.1 \quad 3.0$

Multiple pregnancy

$2.0 \quad 12.1$

$1.4 \quad 11.1$

$1.8 \quad 17.4$

$5.9 \quad 16.0$

$3.9 \quad 7.5$

Gestational age

$\geq 37$ weeks

$93.3 \quad 4.4$

$94.3 \quad 4.2$

$95.2 \quad 6.3$

$81.9 \quad 3.7$

$91.0 \quad 3.1$

$<37$ weeks

$6.7 \quad 6.0$

$5.7 \quad 5.9$

$4.8 \quad 8.3$

$18.1 \quad 6.6$

$9.1 \quad 3.9$

Pre-eclampsia

Yes

$2.2 \quad 7.4$

$1.3 \quad 8.9$

$2.7 \quad 12.1$

$8.1 \quad 4.6$

$4.8 \quad 4.1$

No

$97.8 \quad 4.2$

$98.7 \quad 4.1$

$97.3 \quad 6.1$

$91.9 \quad 3.9$

$95.2 \quad 2.8$

Birth weight neonate

$<10^{\text {th }}$ percentile

$9.7 \quad 3.4$

$9.5 \quad 3.5$

$8.5 \quad 4.4$

$12.0 \quad 3.0$

$\begin{array}{ll}11.5 & 1.7\end{array}$

10-90 $0^{\text {st }}$ percentile

$79.7 \quad 4.3$

$81.0 \quad 4.2$

$75.6 \quad 4.3$

$72.3 \quad 3.0$

$>90^{\text {st }}$ percentile

$10.5 \quad 7.0$

$9.5 \quad 6.8$

$125 \quad 107$

$12.4 \quad 5.4$

$16.2 \quad 5.0$

Perinatal death

Yes

$0.8 \quad 7.5$

$0.8 \quad 7.3$

$0.4 \quad 10.3$

$1.0 \quad 8.8$

$0.7 \quad 5.5$

No

$99.2 \quad 4.5$

$99.2 \quad 4.3$

$99.6 \quad 6.4$

$99.0 \quad 4.2$

$99.3 \quad 3.2$

Medical interventions

Induction of labor

Yes

No

Delivery

Spontaneous

Assisted vaginal delivery

Elective CS

Emergency CS

$\begin{array}{ll}14.8 & 6.2 \\ 85.2 & 4.2\end{array}$

$74.7 \quad 4.3$

$10.7 \quad 6.4$

$\begin{array}{ll}6.5 & 4.3\end{array}$

$8.1 \quad 3.2$

$71.4 \quad 3.8$

Intact/ $\leq 1^{\text {st }}$ degree rupture

$28.6 \quad 6.3$
$14.0 \quad 6.3$

$86.0 \quad 4.0$

NA

NA

NA

NA

$\begin{array}{ll}74.0 & 3.7 \\ 26.0 & 6.2\end{array}$
NA

NA

$81.3 \quad 5.9$

NA

NA

NA

NA

$14.8 \quad 5.1$

$85.2 \quad 6.6$
NA

NA

NA

NA

NA

$99.2 \quad 3.2$

NA

$0.8 \quad 3.6$ 
Table 1 Maternal characteristics, pregnancy characteristics, medical interventions, health care setting and severe PPH incidences (Continued)

\begin{tabular}{|c|c|c|c|c|c|c|c|c|c|c|}
\hline \multicolumn{11}{|l|}{ Manual placenta removal } \\
\hline Yes & 1.9 & 58.3 & 2.0 & 59.6 & 3.8 & 53.2 & NA & & NA & \\
\hline No & 98.1 & 3.5 & 98.0 & 3.2 & 96.2 & 4.6 & NA & & NA & \\
\hline \multicolumn{11}{|l|}{ Health care setting } \\
\hline \multicolumn{11}{|l|}{ Delivery } \\
\hline Home (community midwife) & 24.2 & 2.3 & 32.4 & 2.2 & NA & & NA & & NA & \\
\hline Hospital (community midwife) & 10.9 & 4.2 & 14.6 & 4.2 & NA & & NA & & NA & \\
\hline Tertiary care Hospital & 5.8 & 7.4 & 4.8 & 7.3 & 7.3 & 8.1 & 11.5 & 7.9 & 8.7 & 6.5 \\
\hline Teaching Hospital & 30.4 & 5.6 & 25.1 & 6.0 & 46.9 & 6.6 & 44.4 & 4.0 & 45.4 & 3.1 \\
\hline Non-teaching Hospital & 28.8 & 4.7 & 23.2 & 5.0 & 45.9 & 5.9 & 44.1 & 3.6 & 45.9 & 2.7 \\
\hline
\end{tabular}

Total deliveries: 1599867, PPH unknown: 44859, Mode of delivery unknown: 2350. $\mathrm{NA}=$ not applicable, $\mathrm{CS}=$ cesarean

women who had never given birth) or multiparous women (i.e., women who had given birth at least once). Ethnicity was categorized in Western or non-Western. Social economic status (SES) was derived from the recorded zip code of the women [23]. Gestational age at delivery was categorized into $\geq 37$ weeks and $<37$ weeks. Preeclampsia was defined as a diastolic blood pressure of minimal $90 \mathrm{mmHg}$ in the presence of proteinuria after 20 weeks of gestation [24]. Birth weight percentiles were derived from sex and parity specific growth curves [25] and considered to be undefined for multiple pregnancies and neonates with congenital anomalies or perinatal death. We distinguished between spontaneous onset of labor and induction of labor. Mode of delivery was categorized into spontaneous vaginal, assisted vaginal delivery, elective CS or emergency CS. Perineal laceration was split into 'none or first degree' or 'at least second degree' and a distinction between spontaneous and manual placental delivery was made. The Dutch health care setting was described in more detail above. In case of a discrepancy between LVR1 and LVR2 source data, LVR2 data prevailed, with the exception for the variable ethnicity.

A funnel plot was created using Excel. Tests for differences between groups were performed using SPSS; multilevel analyses were performed using proc glimmix in SAS version 9.3 software.

\section{Results}

We studied a total of 1599867 women. General characteristics of their deliveries are tabulated in Table 1. Severe $\mathrm{PPH}$ was reported in 69719 (4.5\%) of all deliveries; and severe $\mathrm{PPH}$ incidence increased from 3.8 to $5.8 \%$ during the study period ( $\mathrm{p}<0.001$ ). PPH was unknown in 44859 deliveries.

When classified according to mode of delivery, the incidence of severe $\mathrm{PPH}$ was $4.3 \%$ after spontaneous delivery, 6.4\% after assisted vaginal delivery and 4.3\% and $3.2 \%$ after elective CS and emergency CS respectively.

\section{Severe PPH incidence per region}

Additional file 1 tabulates the crude incidence across regions.

\section{Crude incidence}

Figure 1 demonstrates the wide variation in crude incidence per region in relation to the regional population size. After stratification by mode of delivery, the incidence of severe PPH was up to 3 times higher in the region with the highest incidence compared to that with the lowest. In Figure 2 the crude incidence of $\mathrm{PPH}$ following spontaneous delivery is demonstrated per region. After spontaneous delivery, the incidence ranged from $3.3 \%$ to $5.1 \%$. After assisted vaginal delivery this range was $4.8 \%$ to $7.9 \%$ while the ranges after elective and emergency CS were $2.7 \%$ to $6.8 \%$ and $1.5 \%$ to $4.9 \%$, respectively. Without stratification for mode of delivery, the crude severe PPH incidence in the four cities was $4.9 \%$ compared to $4.4 \%$ in the provinces ( $\mathrm{p}<0.001$ ).

\section{Singleton pregnancies}

After exclusion of multiple pregnancies, the average crude incidence of severe PPH was $4.2 \%$ after spontaneous delivery, $6.2 \%$ after assisted vaginal delivery, and 3.5\% and 3.0\% after elective and emergency $\mathrm{CS}$, respectively (Additional file 1). In most regions, the incidence of severe PPH decreased after exclusion of multiple pregnancies. When classified per mode of delivery, regional ranks in the incidence of severe PPH remained similar.

\section{Logistic multilevel regression analyses}

Table 2 shows the OR's of severe PPH per region taking into account the level 'hospital or community midwife 


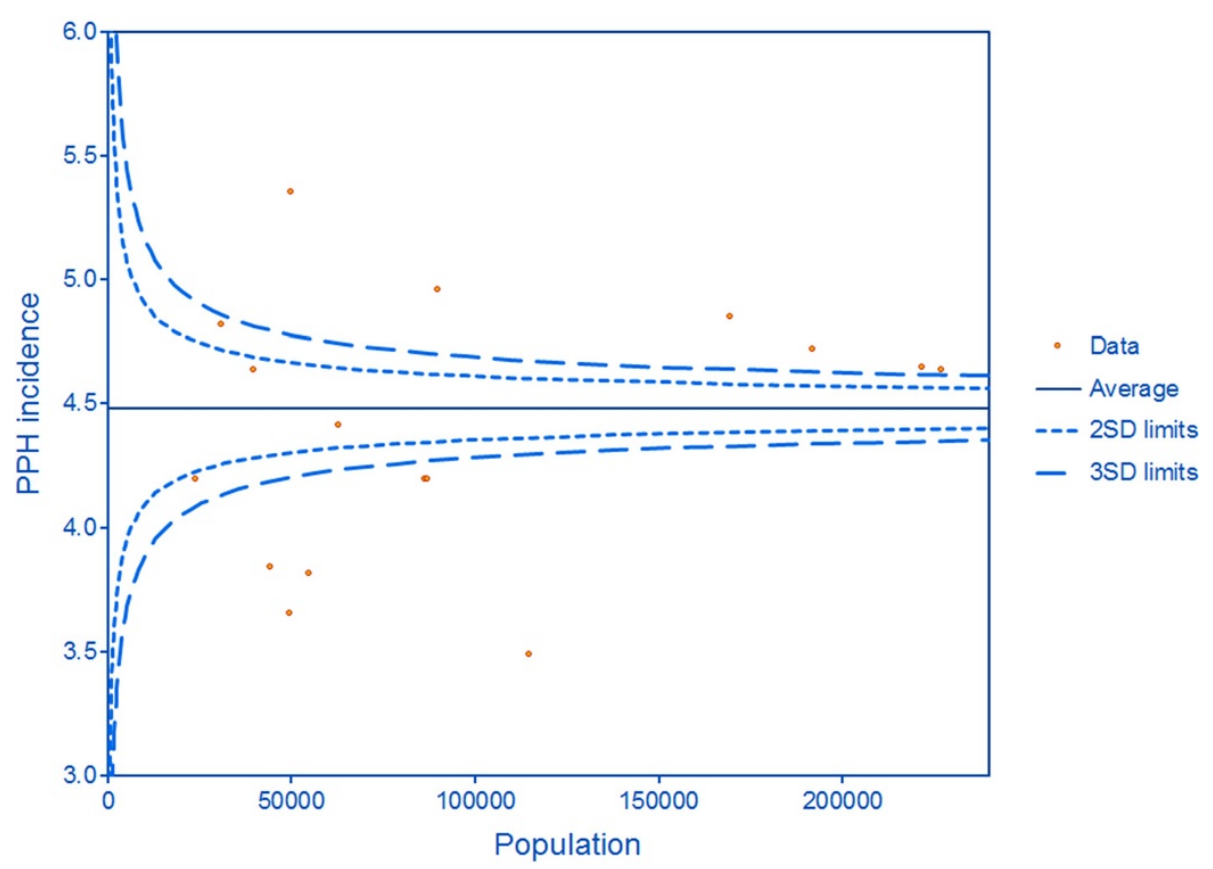

Figure 1 Funnel plot: variation in regional severe PPH incidence related to regional population size.

practice'. Crude, unadjusted regional OR's of the first model ranged from 0.80 to 1.10 . The OR's of severe $\mathrm{PPH}$ in the four largest cities were similar to those in the provinces.

Adjustment for maternal characteristics led to higher OR's compared to the first unadjusted model. Most differences were relatively small except for the cities Amsterdam and Rotterdam. Compared to the first unadjusted model, adjustment for pregnancy characteristics revealed overall lower OR's while adjustment for medical interventions led to an ambiguous effect on the OR's. Adjustment for health care setting also produced an ambiguous effect with mainly higher OR's compared to the first unadjusted model. Of the four blocks of covariates that were added to the first unadjusted model, pregnancy characteristics and health care had the strongest impact on the OR's.

Compared to the unadjusted model, adjustment for all blocks simultaneously had the largest effect on the severe PPH OR's, although this effect was ambiguous.

After adjustment for all blocks, the regional variation in severe PPH OR was largest.

After stratification for mode of delivery, adjustment for all blocks demonstrated ambiguous effects for each mode of delivery too (data not shown).

\section{Severe PPH incidence in Amsterdam}

Additional file 2 tabulates the crude incidence of $\mathrm{PPH}$ across neighborhoods in Amsterdam.

\section{Crude incidence}

The average crude $\mathrm{PPH}$ incidence was $5.0 \%$. There was a wide variation in incidence across neighborhoods with differences between neighborhoods up to $7.3 \%$, depending on the mode of delivery. After spontaneous delivery, the incidence ranged from $3.6 \%$ to $6.4 \%$, after assisted vaginal delivery from $3.8 \%$ to $10.4 \%$ while the ranges after elective and emergency CS showed the widest variation: $1.6 \%$ to $8.9 \%$ and $0.8 \%$ to $5.3 \%$, respectively.

\section{Singleton pregnancies}

After exclusion of multiple pregnancies, the average crude incidence was $4.9 \%$ after spontaneous delivery, $7.4 \%$ after assisted vaginal delivery, $3.7 \%$ after elective CS and $2.4 \%$ after emergency CS.

\section{Severe PPH incidence in Rotterdam}

Additional file 3 tabulates the crude incidence of $\mathrm{PPH}$ across neighborhoods in Rotterdam.

\section{Crude incidence}

The average crude $\mathrm{PPH}$ incidence was $4.4 \%$. Again, differences between neighborhoods were large, with a maximum difference of $8.0 \%$. The incidence differed from $3.8 \%$ to $6.2 \%$ for spontaneous delivery, from $4.1 \%$ to $12.1 \%$ for assisted vaginal delivery while variation was largest for elective and emergency CS: $1.8 \%$ to $6.6 \%$ and $0 \%$ to $4.9 \%$, respectively. 


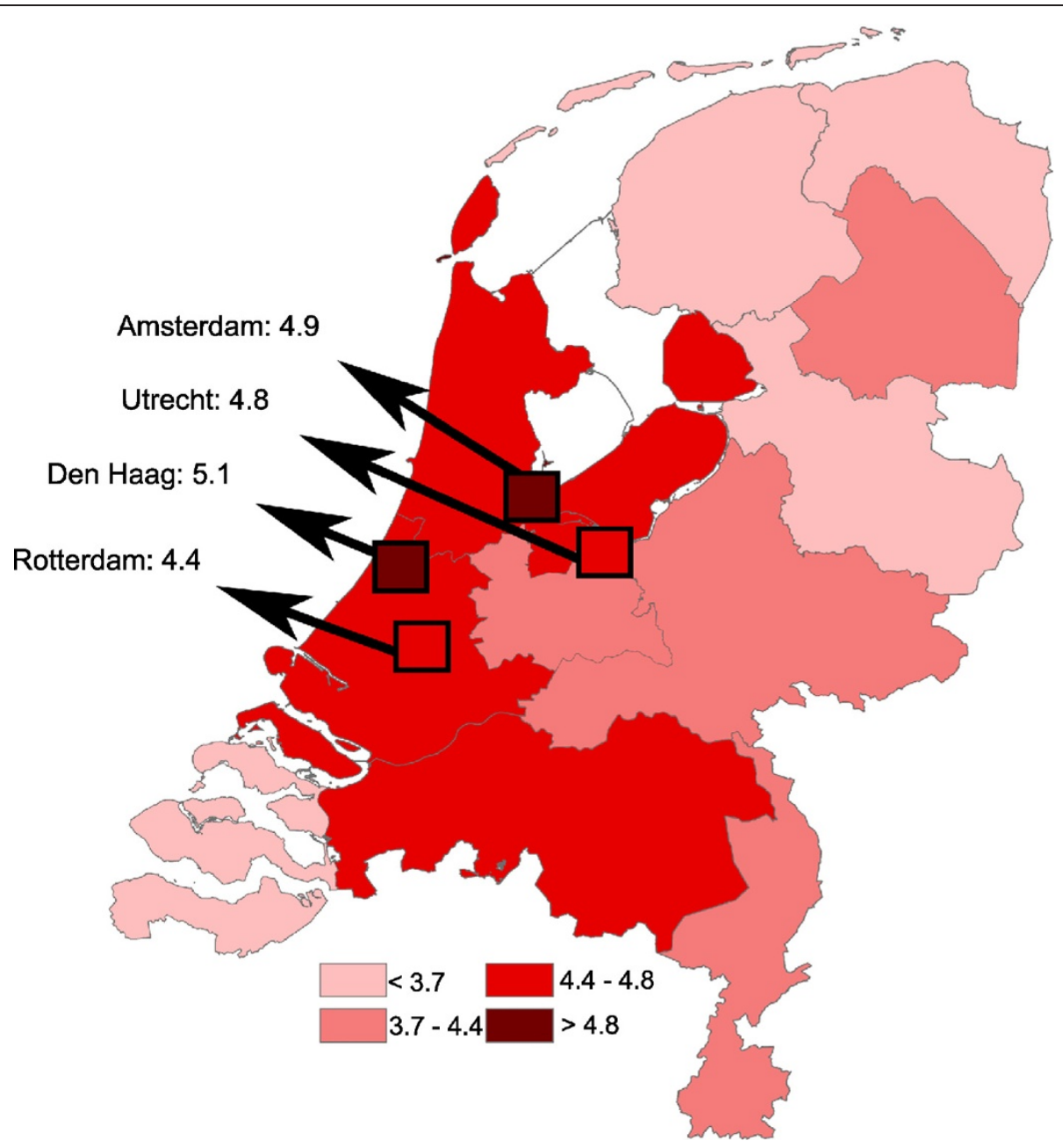

Figure 2 Crude incidence of severe PPH following spontaneous delivery per region.

\section{Singleton pregnancies}

Average crude incidence after exclusion of multiple pregnancies was $4.3 \%$ after spontaneous delivery, 5.3\% after assisted vaginal delivery and 3.4 and $3.2 \%$ after elective and emergency CS.

\section{PPH-related mortality}

Almost eight percent of total Dutch maternal mortality was related to $\mathrm{PPH}$ (see Table 3). PPH-related mortality varied from $0.16 \%$ to $0.59 \%$ across regions. It showed a pattern dissimilar from the pattern of crude severe $\mathrm{PPH}$ incidence across regions.

\section{Discussion}

In this study, we found a wide variation in severe $\mathrm{PPH}$ incidence across regions (provinces, cities) and neighborhoods in the Netherlands, with crude incidences ranging from below $2 \%$ to well over $8 \%$. In women with elective and emergency $\mathrm{CS}$, the variation in severe $\mathrm{PPH}$ incidence was the most extreme. As expected, exclusion of multiple pregnancies decreased crude incidences. The incidence of severe $\mathrm{PPH}$ was higher in the four cities. After logistic multilevel regression analyses, in which we controlled for maternal characteristics, pregnancy characteristics, medical interventions and health care setting, the variation per region even increased (Table 2). Apparently, the epidemiological data cannot elucidate the sources of the remnant variation: results imply they are random or subsequent to regional variation of a yet unregistered variable. Results from our study imply that this unregistered variable is most likely to be found among differences in care and management (professional performance). It is known that adherence to clinical guidelines in on average questionable [26,27] and differences may exist between local protocols. Therefore, results of this study should lead to audit programs to investigate causes.

Regional differences in PPH incidence have been described previously. Carolli et al. [5] reported similar variation in severe $\mathrm{PPH}$ incidence worldwide while Fong 
Table 2 Results of logistic multilevel regression analyses of PPH per region

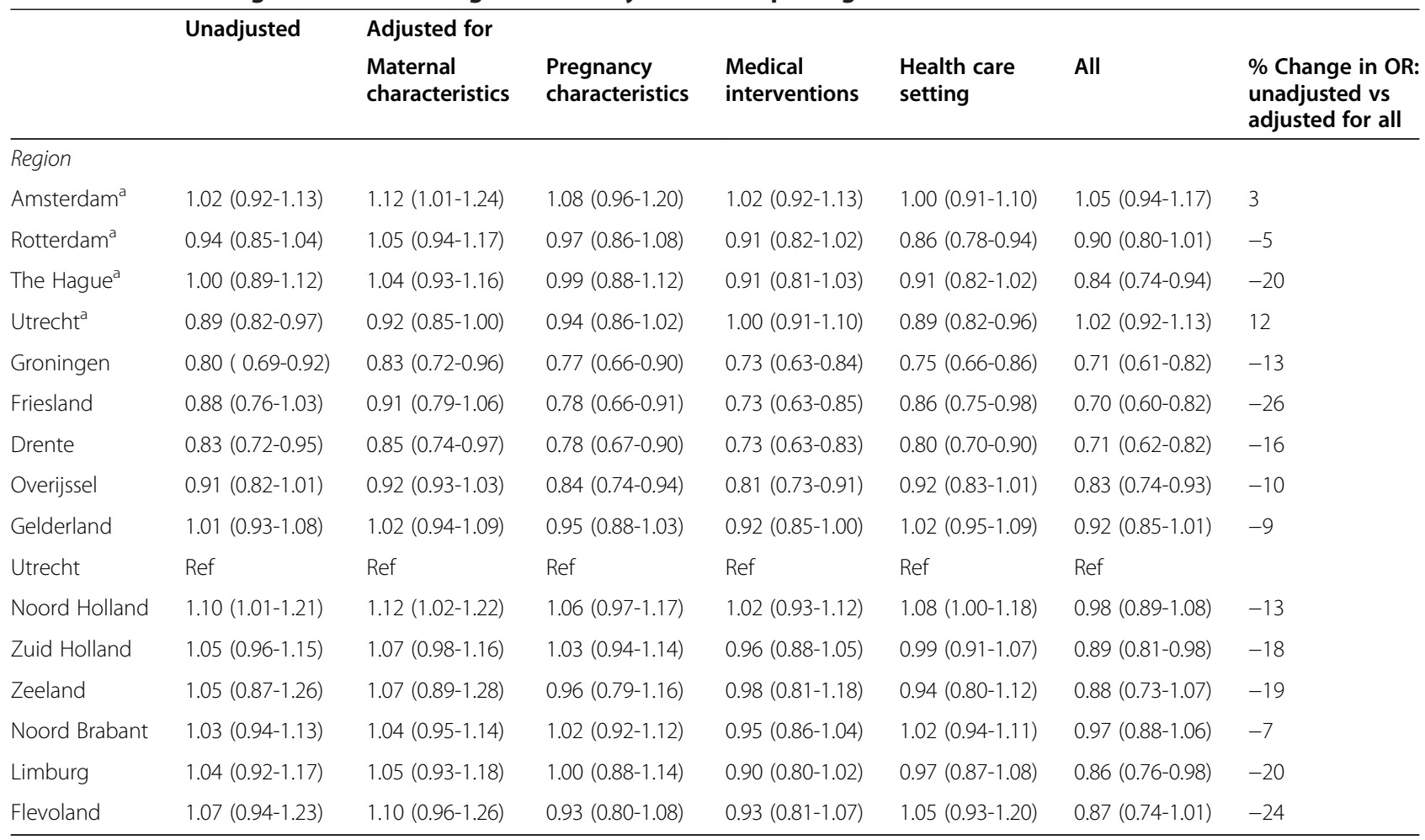

${ }^{\mathrm{a}}$ City.

Level used was the unique code for each hospital and community midwife practice.

Maternal characteristics: Age, Parity, Ethnicity, SES.

Pregnancy characteristics: Singleton pregnancy, Gestational age, Birth weight, Pre-eclampsia, Perinatal Death.

Medical interventions: Induction of labor, Mode of delivery, Perineal laceration, Placental removal.

Health care setting: Place of delivery.

et al. [15] reported variation in California. These studies did not explore the causes of these variations. In addition, $\mathrm{Lu}$ et al. found large differences across hospitals in California and also found higher incidences of obstetrical trauma, chorioamnionitis, and protracted labor (used as proxy of the quality of health care) in hospitals with a high PPH incidence [28].

Known risk factors for PPH can be divided in maternal characteristics, pregnancy characteristics, medical interventions and health care setting. Higher PPH incidences have been reported in women with increased age or decreasing SES, while data regarding ethnicity and parity are contradictive [3,29-33]. Beside these maternal characteristics, other risk factors for $\mathrm{PPH}$ that have been described in the literature are induction of labor, augmentation of labor, perineal laceration, manual placental removal and an increasing fetal weight $[3,29,30]$. Additionally, variation in Dutch obstetric care, regarding the obstetric intervention rate, has previously been described [34]. Although these risk factors varied to a large extent across regions (data not shown), PPH variation remained after adjustment for these factors.

In this study, we presented the geographical distribution while taking into account hospital or community midwife practice (because on average $24 \%$ of women in the Netherlands deliver at home [18]). Regarding place of birth, no relation to the occurrence of $\mathrm{PPH}$ was reported by Davis et al. in a recent study [35] while de Jonge et al. reported lower rates of PPH in women with planned home birth [36].

The incidence of severe PPH depended on mode of delivery, and classified by mode of delivery, variation was not uniform. Although this finding has been reported in previous studies, too $[5,9,11,37]$, the relatively low severe PPH incidence after (emergency) CS was remarkable. Overall, mean blood loss during delivery is higher in case of CS [38]. An explanation for the lower rate of severe $\mathrm{PPH}$ might be that during surgery adequate measures to control the bleeding are more quickly available than at the delivery ward. Alternatively, there might be the possibility of registration errors. The magnitude of such errors, however, is not expected to vary across regions and will therefore not have influenced the variation across regions to a great extent.

In this study, almost $8 \%$ of maternal mortality was related to $\mathrm{PPH}$; the incidence of maternal mortality related to PPH varied across regions between 0.16 and $0.59 \%$. In California, PPH-related mortality across regions has 
Table 3 Crude maternal mortality per region

\begin{tabular}{|c|c|c|c|c|}
\hline & Deliveries $^{a}$ & $\begin{array}{l}\text { Severe } \\
\mathrm{PPH}^{\mathrm{a}}\end{array}$ & $\begin{array}{l}\text { Total } \\
\text { mortality } \\
\text { (all causes) }^{\mathrm{b}}\end{array}$ & $\begin{array}{l}\text { Mortality, due } \\
\text { to severe } \mathrm{PPH}^{\mathrm{b}} \\
\text { (\% of total } \\
\text { mortality) }\end{array}$ \\
\hline & $\mathbf{n}$ & $\mathrm{n}$ & $\mathrm{n}$ & $\mathbf{n}$ \\
\hline \multicolumn{5}{|l|}{ Region } \\
\hline Amsterdam $^{c}$ & 90738 & 4656 & 9 & 0 \\
\hline Rotterdam ${ }^{c}$ & 63571 & 2891 & 17 & 1 \\
\hline Den Haag ${ }^{c}$ & 53509 & 2812 & 9 & 0 \\
\hline Utrecht $^{c}$ & 37098 & 1583 & 4 & 0 \\
\hline Groningen & 50823 & 1912 & 5 & 0 \\
\hline Friesland & 56079 & 2201 & 7 & 1 \\
\hline Drente & 44942 & 1795 & 6 & 1 \\
\hline Overijssel & 118003 & 4227 & 15 & 2 \\
\hline Gelderland & 197320 & 9575 & 15 & 1 \\
\hline Utrecht & 93408 & 3828 & 19 & 3 \\
\hline Noord Holland & 173166 & 8613 & 16 & 0 \\
\hline Zuid Holland & 226040 & 10843 & 20 & 2 \\
\hline Zeeland & 27505 & 1047 & 6 & 1 \\
\hline Noord Brabant & 230043 & 11081 & 20 & 1 \\
\hline Limburg & 88794 & 3833 & 10 & 0 \\
\hline Flevoland & 40107 & 1941 & 5 & 0 \\
\hline Unknown region & 8721 & 430 & 4 & 1 \\
\hline Total & 1599867 & 73268 & 187 & $14(7.5 \%)$ \\
\hline
\end{tabular}

${ }^{\mathrm{a}}$ Data derived from PRN.

${ }^{\mathrm{b}}$ Data derived from Maternal Mortality Committee. 'City.

been described to vary between 0.08 and $0.21 \%$ [15]. In our study, variation was thus larger. An explanation for the wider variation may be that our dataset was smaller. Haeri et al. reported $13 \%$ of maternal mortality in developed countries to be caused by PPH [39]. The variation of mortality in our study was not comparable to the variation pattern of severe $\mathrm{PPH}$, unlike findings of Fong et al. [15]. Again, mortality numbers in our study were very small.

The following limitations of this study have to be considered. Despite our large dataset, the number of deliveries in some neighborhoods were relatively small. Also, a small number of care providers did not participate in the PRN (5\% of community midwife practices, $1 \%$ of gynecologists), but it is that unlikely non-participation is related to the occurrence of PPH. Another limitation concerns data on other PPH determinants. Data on body mass index (BMI) data were unavailable, which is worrisome as $\mathrm{BMI}$ is proposed to be a risk factor for $\mathrm{PPH}$ [40-42] and Dutch public health reports show regional BMI variation [43]. However, at the aggregate level epidemiological patterns apparently do not relate. Also, data on active third stage management and professional performance were unavailable.

Although literature has shown that estimation of the amount of blood loss is often inaccurate [38,44,45], blood loss is not routinely weighed in the Netherlands in all deliveries. After vaginal deliveries blood loss is mostly estimated in case of normal blood loss and usually weighed in case of persisting blood loss. In case of CS, abdominal blood loss is collected through suction in a measuring pot and estimated postoperatively based on the amount of fluid in the pot and the vaginal blood loss. To our knowledge, no validation studies on blood loss estimation have been performed in the Netherlands. Blood loss is recorded in the PRN dataset as a binary variable with a cutoff of $1000 \mathrm{~mL}$ (irrespective of the mode of delivery). This cutoff was derived from the definition of severe postpartum hemorrhage by the World Health Organization [14] and is the most widely used in literature. While blood loss of $1000-2000 \mathrm{~mL}$ is usually not a major threat to the maternal condition in developed countries, we believe this cutoff is accurate. Results with this cutoff are more trustworthy due to the (relatively) large number of cases than with a higher cutoff. However, in our dataset the method for blood loss measurement is not registered and might vary. Consequently, reported differences in severe PPH incidence might have their origin also in regional differences in methods of measurements. Despite the inaccuracy of the blood estimation procedure in general [46], we assume the cutoff of $1000 \mathrm{~mL}$ to be sufficiently accurate for our purposes, as the great majority of such cases will involve weighed blood loss. Bias through differences in these estimations is expected to be small as, if present, misclassification is expected to be similar across regions. The major weakness in the dataset is the lack of registration of preventive and therapeutic measures.

The major strength of this study is the very large dataset containing $96 \%$ of all deliveries in the Netherlands in the period 2000-2008. These numbers strengthen external validity of the study. Since data were extracted electronically from the medical records, data are trustworthy. Data were prechecked through built-in checks and through post-hoc algorithms of the PRN; note however that the dataset was anonymized excluding the potential for individual retrospective checks.

\section{Conclusions}

A large variation in severe PPH incidence exists nationwide in the Netherlands. This variation could not be explained by maternal characteristics, pregnancy characteristics, medical interventions or health care setting. Regional variation may be random or subsequent to regional variation of a yet unregistered variable. 


\section{Additional files}

\section{Additional file 1: Crude incidences of $\mathrm{PPH}$ per region. \\ Additional file 2: Crude incidences of PPH in Amsterdam. \\ Additional file 3: Crude incidences of PPH in Rotterdam.}

\author{
Abbreviations \\ BMI: Body Mass Index; CS: Cesarean Section; MMC: Maternal Mortality \\ Committee; PRN: Netherlands Perinatal Registry; PPH: Postpartum \\ Hemorrhage; SES: Social Economic Status.
}

\section{Competing interests}

The authors declare that they have no competing interests.

\section{Authors' contributions}

BWP, JFSA, CWPMH, KWMB, BWM and JJD participated in the design of the study. BWP, JFSA, CWPMH, GJB performed the statistical analysis while BWP, JFSA, CWPMH, GJB, EAPS, BWM, JMS, KWMB and JJD interpreted results. BWP and JJD drafted the manuscript while all authors revised the draft. All authors read and approved the final manuscript.

\section{Acknowledgements}

We would like to thank the Netherlands Perinatal Registry and Dutch Maternal Mortality Committee for their support and advice. Furthermore, we thank Gerard Borsboom, for his support with multilevel analyses in SAS, Jashvant Poeran for creating the geographic figure and Khalid Khan for editorial advice.

\section{Author details}

'Department of Obstetrics and Gynecology, Division of Obstetrics \& Prenata Medicine, Erasmus MC, 's-Gravendijkwal 230, 3015, CE Rotterdam, The Netherlands. ${ }^{2}$ Department of Obstetrics and Gynecology, Maasstad Hospital, Maasstadweg 21, 3079, DZ Rotterdam, the Netherlands. ${ }^{3}$ Department of Obstetrics, Leiden University Medical Centre, Albinusdreef 2, 2333, ZA Leiden, The Netherlands. ${ }^{4}$ The Netherlands Perinatal Registry, Mercatorlaan 1200, 3528BL Utrecht, The Netherlands. ${ }^{5}$ Robinsion Research Institute, School of Pediatrics and Reproductive Health, University of Adelaide, Adelaide 5000, SA, Australia. ${ }^{6}$ Department of Obstetrics and Gynecology, Isala Klinieken, Groot Wezenland 20,8011, JW Zwolle, The Netherlands.

Received: 18 August 2014 Accepted: 6 February 2015 Published online: 21 February 2015

\section{References}

1. World Health Organisation. Maternal mortality in 2000; estimates developed by WHO, UNICEF, and UNFPA. Geneva: World Health Organisation; 2004.

2. AbouZahr C. Global burden of maternal death and disability. Br Med Bull. 2003:67:1-11.

3. Oyelese $Y$, Ananth CV. Postpartum hemorrhage: epidemiology, risk factors, and causes. Clin Obstet Gynecol. 2010;53(1):147-56.

4. Khan KS, Wojdyla D, Say L, Gulmezoglu AM, Van Look PF. WHO analysis of causes of maternal death: a systematic review. Lancet. 2006;367(9516):1066-74.

5. Carroli G, Cuesta C, Abalos E, Gulmezoglu AM. Epidemiology of postpartum haemorrhage: a systematic review. Best Pract Res Clin Obstet Gynaecol. 2008:22(6):999-1012

6. Bateman BT, Berman MF, Riley LE, Leffert LR. The epidemiology of postpartum hemorrhage in a large, nationwide sample of deliveries. Anesth Analg. 2010;110(5):1368-73.

7. Callaghan WM, Kuklina EV, Berg CJ. Trends in postpartum hemorrhage: United States, 1994-2006. Am J Obstet Gynecol. 2010;202(4):353. e351-356.

8. Knight M, Callaghan WM, Berg C, Alexander S, Bouvier-Colle MH, Ford JB, et al. Trends in postpartum hemorrhage in high resource countries: a review and recommendations from the International Postpartum Hemorrhage Collaborative Group. BMC Pregnancy Childbirth. 2009:9:55.

9. Joseph KS, Rouleau J, Kramer MS, Young DC, Liston RM, Baskett TF. Investigation of an increase in postpartum haemorrhage in Canada. BJOG. 2007;114(6):751-9

10. Cameron $\mathrm{CA}$, Roberts $\mathrm{CL}$, Olive EC, Ford JB, Fischer WE. Trends in postpartum haemorrhage. Aust N Z J Public Health. 2006:30(2):151-6.
11. Ford JB, Roberts CL, Simpson JM, Vaughan J, Cameron CA. Increased postpartum hemorrhage rates in Australia. Int J Gynaecol Obstet. 2007;98(3):237-43

12. Rossen J, Okland I, Nilsen OB, Eggebo TM. Is there an increase of postpartum hemorrhage, and is severe hemorrhage associated with more frequent use of obstetric interventions? Acta Obstet Gynecol Scand. 2010;89(10):1248-55.

13. Lutomski JE, Byrne BM, Devane D, Greene RA. Increasing trends in atonic postpartum haemorrhage in Ireland: an 11-year population-based cohort study. BJOG. 2012;119(3):306-14.

14. World Health Organisation. WHO guidelines for the management of postpartum haemorrhage and retained placenta. Geneva: World Health Organisation; 2009

15. Fong A, Leake J, Pan D, Ogunyemi D. Demographic, institutional and obstetrical risk factors for postpartum haemorrhage mortality. J Obstet Gynaecol. 2010;30(5):470-5

16. Schutte JM, Steegers EA, Schuitemaker NW, Santema JG, de Boer K, Pel M, et al. Rise in maternal mortality in the Netherlands. BJOG. 2010;117(4):399-406.

17. Registry TNP. Perinatal care in The Netherlands 2006 (in Dutch: Perinatalezorg in Nederland 2006). Utrecht: The Netherlands Perinatal Registry; 2008.

18. van der Kooy J, Poeran J, de Graaf JP, Birnie E, Denktass S, Steegers EA, et al. Planned home compared with planned hospital births in the Netherlands: intrapartum and early neonatal death in low-risk pregnancies. Obstet Gynecol. 2011;118(5):1037-46.

19. De Graaf J, Schutte J, Poeran J, van Roosmalen J, Bonsel G, Steegers E. Regional differences in Dutch maternal mortality. BJOG. 2012;119(5):582-8.

20. de Graaf JP, Ravelli AC, de Haan MA, Steegers EA, Bonsel GJ. Living in deprived urban districts increases perinatal health inequalities. J Matern Fetal Neonatal Med. 2013;26(5):473-81.

21. de Graaf JP, Steegers EA, Bonsel GJ. Inequalities in perinatal and maternal health. Curr Opin Obstet Gynecol. 2013;25(2):98-108.

22. Al-Zirqi I, Vangen S, Forsen L, Stray-Pedersen B. Effects of onset of labor and mode of delivery on severe postpartum hemorrhage. Am J Obstet Gynecol. 2009;201(3):273. e271-279.

23. The Netherlands Institute for Social Research: http://www.scp.nl/Onderzoek/ Lopend_onderzoek/A_Z_alle_lopende_onderzoeken/Statusscores. The Hague: The Netherlands Institute for Social Research 2006: accessed July 2012.

24. Brown MA, Lindheimer MD, de Swiet M, Van Assche A, Moutquin JM. The classification and diagnosis of the hypertensive disorders of pregnancy: statement from the International Society for the Study of Hypertension in Pregnancy (ISSHP). Hypertens Pregnancy. 2001;20(1):IX-XIV.

25. Visser GH, Eilers PH, Elferink-Stinkens PM, Merkus HM, Wit JM. New Dutch reference curves for birthweight by gestational age. Early Hum Dev. 2009;85(12):737-44.

26. Prick BW, Vos AA, Hop WC, Bremer HA, Steegers EA, Duvekot JJ. The current state of active third stage management to prevent postpartum hemorrhage: a cross-sectional study. Acta Obstet Gynecol Scand. 2013;92(11):1277-83.

27. Grol R, Grimshaw J. From best evidence to best practice: effective implementation of change in patients' care. Lancet. 2003;362(9391):1225-30.

28. Lu MC, Fridman M, Korst LM, Gregory KD, Reyes C, Hobel CJ, et al. Variations in the incidence of postpartum hemorrhage across hospitals in California. Matern Child Health J. 2005;9(3):297-306.

29. Al-Zirai I, Vangen S, Forsen L, Stray-Pedersen B. Prevalence and risk factors of severe obstetric haemorrhage. BJOG. 2008;115(10):1265-72.

30. Bais JM, Eskes M, Pel M, Bonsel GJ, Bleker OP. Postpartum haemorrhage in nulliparous women: incidence and risk factors in low and high risk women. A Dutch population-based cohort study on standard (> or $=500 \mathrm{ml}$ ) and severe $(>$ or $=1000 \mathrm{ml}$ ) postpartum haemorrhage. Eur J Obstet Gynecol Reprod Biol. 2004;115(2):166-72

31. Combs CA, Murphy EL, Laros Jr RK. Factors associated with postpartum hemorrhage with vaginal birth. Obstet Gynecol. 1991;77(1):69-76.

32. Biguzzi E, Franchi F, Ambrogi F, Ibrahim B, Bucciarelli $P$, Acaia B, et al. Risk factors for postpartum hemorrhage in a cohort of 6011 Italian women. Thromb Res. 2012;129(4):e1-7.

33. Combs CA, Murphy EL, Laros Jr RK. Factors associated with hemorrhage in cesarean deliveries. Obstet Gynecol. 1991;77(1):77-82.

34. Heres MH, Pel M, Elferink-Stinkens PM, Van Hemel OJ, Treffers PE. The Dutch obstetric intervention study-variations in practice patterns. Int J Gynaecol Obstet. 1995;50(2):145-50. 
35. Davis D, Baddock S, Pairman S, Hunter M, Benn C, Anderson J, et al. Risk of severe postpartum hemorrhage in low-risk childbearing women in New Zealand: exploring the effect of place of birth and comparing third stage management of labor. Birth. 2012;39:98-105.

36. de Jonge A, Mesman JA, Mannien J, Zwart JJ, van Dillen J, van Roosmalen J. Severe adverse maternal outcomes among low risk women with planned home versus hospital births in the Netherlands: nationwide cohort study. BMJ. 2013:346:f3263.

37. Burrows $L$, Meyn LA, Weber AM. Maternal morbidity associated with vaginal versus cesarean delivery. Obstet Gynecol. 2004;103(5 Pt 1):907-12.

38. Stafford I, Dildy GA, Clark SL, Belfort MA. Visually estimated and calculated blood loss in vaginal and cesarean delivery. Am J Obstet Gynecol. 2008:199(5):519. e511-517.

39. Haeri S, Dildy 3rd GA. Maternal mortality from hemorrhage. Semin Perinatol. 2012;36(1):48-55.

40. Blomberg M. Maternal obesity and risk of postpartum hemorrhage. Obstet Gynecol. 2011;118(3):561-8.

41. Paglia MJ, Grotegut CA, Johnson LN, Thames B, James AH. Body mass index and severe postpartum hemorrhage. Gynecol Obstet Invest. 2012;73(1):70-4.

42. Zwart JJ, Dijk PD, van Roosmalen J. Peripartum hysterectomy and arterial embolization for major obstetric hemorrhage: a 2-year nationwide cohort study in the Netherlands. Am J Obstet Gynecol. 2010;202(2):150. e151-157.

43. Mulder M. Overgewicht vrouwen 2005-2008. In: Volksgezondheid Toekomst Verkenning, Nationale Atlas Volksgezondheid Bilthoven: RIVM 2010: https://www.volksgezondheidenzorg.info/, accessed July 2012

44. Bose P, Regan F, Paterson-Brown S. Improving the accuracy of estimated blood loss at obstetric haemorrhage using clinical reconstructions. BJOG. 2006:113(8):919-24.

45. Dildy 3rd GA, Paine AR, George NC, Velasco C. Estimating blood loss: can teaching significantly improve visual estimation? Obstet Gynecol. 2004;104(3):601-6.

46. Duthie SJ, Ven D, Yung GLK, Guang DZ, Chan SYW, Ma HK. Discrepancy between laboratory determination and visual estimation of blood loss during normal delivery. Eur J Obstet Gynecol Reprod Biol. 1990;38:119-24.

\section{Submit your next manuscript to BioMed Central and take full advantage of:}

- Convenient online submission

- Thorough peer review

- No space constraints or color figure charges

- Immediate publication on acceptance

- Inclusion in PubMed, CAS, Scopus and Google Scholar

- Research which is freely available for redistribution 